\title{
The co-movement of couples' incomes
}

\author{
Stephen H. Shore
}

Received: 12 March 2013/Accepted: 28 May 2013/Published online: 23 July 2013

(C) The Author(s) 2013. This article is published with open access at Springerlink.com

\begin{abstract}
While there is a large literature on how individual incomes move over time, we know much less about couples' joint income dynamics. Current research on individual income dynamics has increasingly considered heterogeneity-do all individuals' incomes evolve in the same way, or does a particular individual's income evolve in the same way throughout their life? This paper considers the analogous questions for couples-do all couples' incomes move together in the same way, or does a particular couple's incomes move together in the same way throughout their marriage? In particular, I find evidence of correlated volatility; husbands with volatile incomes tend to have wives with volatile ones. I find weaker evidence for heterogeneity in the correlation of husbands' and wives' income changes, with some couples incomes moving together while others moving in opposite directions. Couples' income changes are negatively correlated early in marriage, particularly when young children are present, and become more positively correlated over time.
\end{abstract}

Keywords Couples · Income dynamics $\cdot$ Heterogeneity $\cdot$ Wife-swap bootstrap

JEL Classification D31-Personal income, wealth, and their distributions .

D13-Household production and intrahousehold allocation .

C33-Multiple equation models with panel data

\section{Introduction}

There is a very large literature on individual income dynamics, on how individuals' incomes evolve over time. Much of this literature is focussed on income volatility,

\footnotetext{
S. H. Shore ( $₫)$

Georgia State University, Atlanta, GA, USA

e-mail: sshore@gsu.edu
} 
the variance of income changes. ${ }^{1}$ Recent work in this area has focused on identifying latent heterogeneity in volatility; some people may face income changes with larger variances than others (Meghir and Pistaferri 2004; Browning et al. 2010; Jensen and Shore 2011; Jensen and Shore 2012).

The literature on couples' joint income dynamics-how couples' incomes move together-is much smaller (Lundberg 1985; Cullen and Gruber 2000; Hyslop 2001; Dynan et al. 2007; Shore 2010). Just as recent research has focussed on heterogeneity in individuals' income dynamics, this paper considers heterogeneity in couples' joint income dynamics; do all couples' incomes move together in the same way? Heterogeneity in couples' joint income dynamics could reflect assortative mating in volatility, so that individuals with volatile incomes tend to marry each other; ${ }^{2}$ it could also reflect heterogeneity in co-movement, so that some couples' incomes move together while other couples' incomes move in opposite directions. Both of these phenomenon show up in the cross-section of couples' income changes as bivariate kurtosis (Mardia 1970, 1974, 1980), the tendency of large (absolute) income changes for husbands and wives to coincide. In years in which a husband's earnings changes substantially (either rising or falling), his wife's income tends to change substantially (either rising or falling) as well. However, correlated volatility can be separated from heterogeneity in co-movoment with panel data or other covariates given certain assumptions.

These distinctions are important for understanding the economic effects of coupling. Positive assortative mating in volatility may be optimal given positive assortative mating in risk-aversion, as predicted by Chiappori and Reny (2006). Risk tolerant individuals may choose risky income streams for themselves, and also seek partners with risky income streams (leading to positive assortative mating on risk-aversion). Conversely, absent heterogeneity in risk-aversion, we would expect negative assortative mating in volatility, as the cost of marrying a high-risk spouse is lower for a low-risk person. Heterogeneity in the covariance of couples' income changes is important because it suggests differences across couples in the risksharing benefits of marriage. Nordblom (2004) shows that some of this variation in the diversification benefits of marriage may stem from differences in legal regimes that my affect the degree of commitment and cooperation while Chami and Hess (2005) shows that there is cross-state variation stemming from differences in states' levels of undiversifiable risk. Hess (2004) shows that such variation can predict divorce.

Changes over time in couples' joint income dynamics suggest changes in labor and leisure complementarities over the life cycle. This paper shows that early in marriage, particular when young children are present, couples' incomes are

\footnotetext{
${ }^{1}$ Papers on this subject include Hall and Mishkin (1982); Gottschalk and Moffitt (1994); Moffitt and Gottschalk (2011); Daly and Duncan (1997); Carroll and Samwick (1997); Dynarski and Gruber (1997); Cameron and Tracy (1998); Geweke and Keane (2000); Haider (2001); Gottschalk and Moffitt (2002); Batchelder (2003); Hacker (2006); Comin et al. (2009); Gottschalk and Moffitt (2006; Hertz (2006); Winship (2007); Bollinger et al.(2009); Leete and Bania (2010); Dahl et al. (2007); Shin and Solon (2011).

${ }^{2}$ Alternatively marriage could make income volatility for husbands and wives more similar than it would have been had they not wed.
} 
negatively correlated. Couples' income changes become more positively correlated as the number of years a couple has been married increases. One possible interpretation of this life-cycle pattern is that it reflects life-cycle changes in the relative importance of various economic benefits of marriage. Early in marriage, one spouse's production may be a substitute for the production of the other; increases in income by one spouse will tend to coincide with increases in home production (and decreases in market work) for their partner. This suggests that the specialization in production described in Becker (1973) is particularly dominant early in marriage. Later in marriage, complementarity of leisure may become more important; this could explain the increasingly positive co-movement of couples' incomes nearing retirement. This phenomenon is studied most frequently in the context of couples' joint retirement decisions, which frequently coincide (Hurd 1990; Burtless 1990; Gustman and Steinmeier 2000; Maestas 2001; Michaud 2003; Casanova 2010). Simultaneous retirement is frequently motivated by leisure complementarities: leisure time in retirement is more enjoyable if you can share this leisure time with your spouse.

These ideas are applied to couples' income data from the Panel Study of Income Dynamics. In the data, wives' income changes are approximately uncorrelated with their husbands' income changes. ${ }^{3}$ However, they are not independent, as couples' squared income changes are positively correlated; there is bivariate kurtosis, so that husbands' large income changes (increases or decreases) tend to coincide with wives' large income changes (increases or decreases). A "wife-swap bootstrap" test strongly rejects the independence of couples income streams, finding substantial bivariate kurtosis. This procedure is appropriate when the pair of random variables (here, husbands' and wives' income changes) are unconditionally uncorrelated but each spouse's income changes may be autocorrelated (as in this case). This test is designed to measure the amount of matching that can be seen in couples' joint income dynamics, relative to a null hypothesis of random pairing; this paper strongly rejects the hypothesis that couples' joint income dynamics resemble what would be expected from random pairing. By comparing results for various measures of income and hours worked, much of this stems from large changes in wives' hours (and not wages per hour) coinciding with large changes in their husbands' incomes.

Correlated volatility can explain much of the observed bivariate kurtosis; wives whose income shocks have large variances tend to be married to husbands whose income shocks also have large variances. Correlated variance parameters explain more than 28 or $90 \%$ (depending on the measure of income changes) of the observed bivariate kurtosis. This looks like the positive assortative mating on income risk of interest to Chiappori and Reny (2006).

Heterogeneity in co-movement-with some couples' incomes moving together while other couples' incomes moving in opposite directions-is also present. This covariance heterogeneity explains $10-33 \%$ of bivariate kurtosis.

\footnotetext{
3 See sample moments from Table 3.
} 


\section{Data}

Data are drawn from the Panel Study of Income Dynamics (PSID). The PSID is a nationally representative panel of U.S. households that has tracked families annually from 1968 to the present. Data are not collected in even-numbered years after 1997; this paper uses data collected through 2005. However, since most analyses use 1-year income changes, only data through 1997 will be used in most circumstances. The PSID includes data on households, including household food consumption and the education, income, hours worked, employment status, and age of husbands and wives. I use annual labor income as a measure of income. I restrict the sample to married couples, to couples where the marriage is the husband's first, to observations for which both the husband and wife are between the ages of 22 and 60 , and for which the couple has been married for no more than 35 years.

I remove the predictable (to the econometrician) component of income and examine the time series properties of the unpredictable component, excess log income. As is common in the literature, this excess log income is the residual from a least-squares regression of the natural log of labor income (for either the husband or the wife) on the following regressors: a cubic in age for each level of educational attainment (none, elementary, junior high, some high school, high school, some college, college, graduate school) for both husband and wife, a cubic in the number of years the couple has been married, the presence and number of infants, young children, and older children in the household, the total number of family members in the household, and dummy variables for each calendar year. ${ }^{4}$ So that log income results are not dominated by income values close to zero, I limit the regression sample to individuals who earn at least $\$ 1,000$ (in 2001 dollars).

The residuals from this regression are Winsorized at the 5th and 95th percentiles, so that residuals below the 5 th percentile are replaced by the 5 th percentile value and those above the 95th percentile are replaced by the 95th percentile value. At the same time, values omitted from the initial regression because real annual income was below $\$ 1,000$ are given the 5th percentile residual value. The vast majority of these initially omitted values have an income of exactly zero. This reduces selection bias by including extreme values, while at the same time limiting the degree to which such outlier drive the results. Even more important, it allows us to exploit variation coming from transitions into and out of the labor force. 1 Year changes are demeaned.

Table 1 presents summary statistics on 1-year changes in excess log income for husbands and wives. Note that most 1 -year excess log income changes are relatively small. The inter-quartile ranges for wives ( $x_{i t}$ from -10 to $8 \%$ ) and husbands $\left(y_{i t}\right.$ from -8 to $10 \%$ ) are modest. However, there are occasional very large changes in income, so that the standard deviations of 1-year income changes (55 and $32 \%$, respectively) are much larger than the inter-quartile ranges. These fat-tails could be the result of fat-tailed shocks (occasional large income changes) or heterogeneity

\footnotetext{
4 This procedure ensures that predictable income changes such as the typical life-cycle pattern of income are not included in measuring couples' idiosyncratic joint income dynamics.
} 
Table 1 Distribution of spouses' 1-year change in excess log income

\begin{tabular}{lcc}
\hline Spouse & Wives & Husbands \\
\hline Mean & 0 & 0 \\
SD & 0.5490 & 0.3184 \\
Observations & 20,762 & 20,762 \\
Minimum & -2.8499 & -1.8283 \\
5th Percentile & -0.8390 & -0.5258 \\
25th Percentile & -0.0955 & -0.0796 \\
50th Percentile & -0.0179 & 0.0064 \\
75 th Percentile & 0.0806 & 0.0987 \\
95th Percentile & 0.9305 & 0.4708 \\
Maximum & 2.8141 & 1.8410 \\
\hline Lag & Autocorrelation & -0.3193 \\
\hline 1 Year & -0.2133 & -0.0445 \\
2 Years & -0.0766 & -0.0217 \\
3 Years & -0.0251 & -0.0169 \\
4 Years & -0.0395 & . \\
\hline
\end{tabular}

This table presents the distributions of 1-year changes in Winsorized excess log income for wives and hubands, $x_{i t}$ and $y_{i t}$, respectively. The construction of Winsorized excess log incomes is explained in the text. In brief, annual log labor incomes for husbands and wives are separately regressed on a host of covariates. The residuals from these regressions are Winsorized at the 5th and 95th percentiles. These changes are de-meaned, so means are zero by construction. The median 1-year change would be exactly zero in the absence of de-meaning, so -1 times the median values gives the average annual change. The sample is limited to observations where data exists in the 6 years prior to the year in question

(some observations are expected to have larger variances while others are expected to have smaller variances, though conditional on these variances tails are not fat).

The patterns of autocorrelation are also presented in Table 1. One-year increases in income tend to be followed by decreases in the following year for both husbands and wives, with very small decreases in subsequent years. While small, autocorrelations at lags greater than one year are larger here than in Abowd and Card (1989), primarily because income changes are Winsorized. Another noteworthy result is that one spouse's income changes are nearly uncorrelated with lagged changes in the other's income.

\section{Results}

\subsection{Income dynamics}

Here, I present a standard income process. Model parameters from this process may differ across couples and over time. While more complex income processes are possible, it is standard in the literature to assume that excess log income is composed of permanent $(p)$ and transitory $(\varepsilon)$ components: 


$$
\begin{aligned}
& z_{y i t}=p_{y i t}+\varepsilon_{y i t} ; \\
& p_{y i t}=p_{y i T_{0}^{i}}+\sum_{\tau=T_{0}^{i}+1}^{t} \omega_{y i \tau} .
\end{aligned}
$$

Here, $z_{y i t}$ refers to the excess $\log$ income of the husband in household $i$ in year $t$. The same process could be applied to wives as well, with $x$ s replacing $y$ s. $x_{i t}$ and $y_{i t}$ will be defined as changes in excess log income over an interval, $x_{i t} \equiv z_{x i t}-z_{x i t-k}$ and $y_{i t} \equiv z_{y i t}-z_{y i t-k}$. In Eq. (1), transitory income, $\varepsilon_{y i t}$, is assumed to be i.i.d. with variance $\left(\sigma_{y \varepsilon}^{2} \mid i t\right)$; permanent income, $p_{y i t}$, is assumed to have a unit root so that innovations to permanent income, $p_{y i t}-p_{y i t-1}=\omega_{y i t}$, are i.i.d. with variance $\left(\sigma_{y \omega}^{2} \mid i t\right)$. Subsequently, "transitory variance" refers to the variance of transitory income, $\left(\sigma_{y z}^{2} \mid i t\right)$; "permanent variance" refers to the variance of innovations to permanent income, $\left(\sigma_{y \omega}^{2} \mid i t\right)$. These conditional variances may differ across individuals and over time.

If husbands' and wives' incomes individually evolve as in Eq. (1), it is natural to consider the joint income process where couples' income shocks may be correlated. For couple $i$ at time $t$, I consider $E\left[\omega_{x i t} \omega_{y i t}\right] \equiv\left(\sigma_{x y \omega} \mid i t\right)$ and $E\left[\varepsilon_{x i t} \varepsilon_{y i t}\right] \equiv\left(\sigma_{x y \varepsilon} \mid i t\right)$, which I subsequently refer to as the "permanent covariance" and the "transitory covariance." While husbands' transitory shocks may be correlated with wives' permanent ones, and vice versa, these cross-covariances are assumed to be zero here.

In this setting, I consider three $\left\{x_{i t}, y_{i t}\right\}$ measures to identify the variancecovariance structure of different types of shocks: raw, permanent, and transitory. Each measure is named by the type of covariance identified by the product of husbands' and wives' income changes, $x_{i t} y_{i t}$. Couples' income change moments for each measure are shown in Table 3

1. Raw The simplest measures of the variance or covariance of income changes come from contemporaneous 1-year changes: $x_{\text {rit }} \equiv z_{x i t}-z_{x i t-1}$ and $y_{\text {rit }} \equiv$ $z_{y i t}-z_{y i t-1}$. These income changes include both permanent and transitory components, so their squares and products will as well. From Table 3 , the unconditional sample mean of $x_{\text {rit }} y_{\text {rit }}$ is close to zero, with an implied correlation of $-0.2 \%$ (statistically insignificant difference from zero).

2. Permanent To isolate the permanent covariance without contamination from the transitory variance, I consider the short-term change in a wife's income and the long-term change in her husband's income that spans this short term change: $x_{\omega} i t \equiv z_{x i t}-z_{x i t-1}$ and $y_{\omega}$ it $\equiv z_{y i t+2}-z_{y i t-3}$. So long as permanent shocks enter in over at most 2 periods and transitory shocks damp out in at most 2 periods [consistent with evidence from Abowd and Card (1989)], this measure isolates the permanent covariance even when the income process is much more general than the one specified here (Meghir and Pistaferri 2004). From Table 3, the unconditional sample mean of $x_{\omega i t} y_{\omega i t}$ is slightly negative but close to zero, with an implied correlation of $-2.6 \%$ (statistically different from zero at the $95 \%$, but not the $99 \%$, significance level). 
3. Transitory Under the specified income process, the transitory covariance can be identified by looking at the product of income changes for one spouse and their lag for the other spouse: $x_{\varepsilon i t} \equiv z_{x i t+1}-z_{x i t}$ and $y_{\varepsilon i t} \equiv z_{y i t-1}-z_{y i t}$. From Table 3, the unconditional sample mean of $x_{\varepsilon i t} y_{\varepsilon i t}$ is slightly negative but close to zero, with an implied correlation of $-0.2 \%$ (statistically insignificant difference from zero).

\subsection{Determinants of co-movement}

While couples' income changes are roughly uncorrelated on average (and insignificantly different from zero using the raw and transitory measures of comovement), the correlation of husbands' and wives' income changes is not zero for every couple or zero at every point in the life cycle. In particular, there is strong lifecycle variation in co-movement. This is apparent in Fig. 1, which is obtained by regressing permanent covariance estimates and variances separately on three-degree polynomials in the number of years of marriage. These coefficients are used to obtain predicted covariance and variance values for each year of marriage. Figure 1 plots the implied correlation for each year of marriage obtained from this procedure, with confidence intervals obtained using the delta method. Permanent innovations to income are strongly negatively correlated early in marriage. This correlation increases with the number of years of marriage. This finding is consistent with results from Shore (2010), which uses repeated observations on the crosssectional covariance of couples' incomes to show that couples' incomes are negatively correlated early in marriage but positively correlated later in marriage. One possible interpretation of this life-cycle pattern is that it reflects life-cycle changes in the relative importance of various economic benefits of marriage. Early in marriage, it may be relatively important that one spouse's production is a substitute for the production of the other; increasing in income by one spouse will tend to coincide by increasing home production and decreasing market work by the other. This would imply the negative co-movement found early in marriage and in the presence of children. Later in marriage, complementarity of leisure may become more important. Working less or retiring early is more appealing when you can spend the additional leisure time with your spouse, which would explain the increasingly positive co-movement of couples' incomes nearing retirement.

Table 2 presents results from regressions to predict co-movement with a host of covariates. The covariance of couples' income changes increases over the lifecycle of marriage. Ceteris paribus, this increases the volatility of household income over time by reducing the diversification benefits of marriage. This will lead to increasing household income inquality over time for older couples (who have many years of compounded permanent shocks). While the presence of children reduces the covariance of couples' income changes, this can be explained fully by the number of years of marriage. There is weak evidence that that couples with high-education husbands and low-education wives have more negative covariances. 


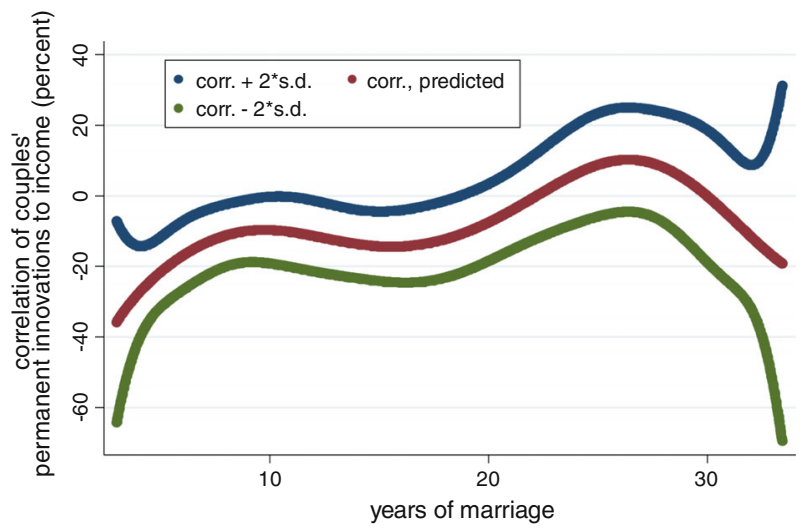

Fig. 1 Co-movement of couples' incomes over the life-cycle. The figure plots the predicted correlation of permanent innovations to income as a function of the number of years of marriage. These are calculated as follows. First, the permanent covariance and permanent variances are calculated for each observation. These are each regressed on a three-degree polynomial in the number of years of marriage, and a predicted value of each is then computed for each possible year of marriage. Correlations are then computed as the ratio of the predicted values. The two standard error confidence intervals are computed using the delta method

Table 2 Determinants of the co-movement of couples' incomes

\begin{tabular}{|c|c|c|c|c|c|c|}
\hline \multirow{2}{*}{$\begin{array}{l}\text { Dependent } \\
\text { variable } \\
\text { \# of Years married }\end{array}$} & \multicolumn{3}{|c|}{ Estimates of the 1-year raw covariance } & \multicolumn{3}{|c|}{$\begin{array}{l}\text { Estimates of the permanent } \\
\text { covariance }\end{array}$} \\
\hline & $\begin{array}{l}0.0013 * * * \\
(4.46)\end{array}$ & & $\begin{array}{l}0.0009 * * * \\
(3.86)\end{array}$ & $\begin{array}{l}0.0010 * * \\
(1.99)\end{array}$ & & $\begin{array}{l}0.0003 \\
(0.85)\end{array}$ \\
\hline \# of Kids & & $\begin{array}{l}-0.0035^{* *} \\
(2.12)\end{array}$ & $\begin{array}{l}-0.0015 \\
(1.17)\end{array}$ & & $\begin{array}{l}-0.0000 \\
(0.02)\end{array}$ & $\begin{array}{l}0.0015 \\
(0.79)\end{array}$ \\
\hline $\begin{array}{c}\text { Husband's } \\
\text { years of } \\
\text { education }\end{array}$ & & & $\begin{array}{l}-0.0014 * * \\
(2.02)\end{array}$ & & & $\begin{array}{l}-0.0017^{*} \\
(1.69)\end{array}$ \\
\hline Wife's years of education & & & $\begin{array}{l}0.0016^{*} \\
(1.88)\end{array}$ & & & $\begin{array}{l}0.0020^{*} \\
(1.66)\end{array}$ \\
\hline Fixed effects? & Yes & Yes & No & Yes & Yes & No \\
\hline Observations & 20,762 & 20,762 & 20,762 & 15,478 & 15,478 & 15,478 \\
\hline$R^{2}$ & 0.0010 & 0.0002 & 0.0015 & 0.0003 & 0.0000 & 0.000 \\
\hline
\end{tabular}

This table shows results from OLS regressions that predict permanent and 1-year raw covariance estimates with covariates. $t$ statistics in parentheses. "** "**" and "***" Indicate significance at the 10, 5, and $1 \%$ levels, respectively

\subsection{Heterogeneity in couples' joint income dynamics}

The sample moments from Table 3 provides the moments needed to test for bivariate kurtosis, the tendency of couples large (absolute) income changes to coincide. The top panel of Table 4 presents the results of these tests, showing substantial and statistically significant bivariate kurtosis. The significance of the results is slightly higher using the "wife-swap bootstrap" test discussed in the Appendix. This test relaxes the 
Table 3 Sample moments for couples' income changes

\begin{tabular}{llll}
\hline Covariance measure & Raw & Permanent & Transitory \\
\hline$x_{i t}$ : wife's income change & 1 Year & 1 Year & 1 Year \\
$y_{i t}$ : husband's income change & Same & Surrounding & Lagged \\
& 1 year & 5 years & 1 year \\
$x_{i t}$ & 0 & 0.0044 & 0.0005 \\
$x_{i t}^{2}$ & 0.3013 & 0.2970 & 0.3028 \\
$x_{i t}^{4}$ & 0.8560 & 0.8235 & 0.8540 \\
$y_{i t}$ & 0 & 0.0059 & -0.0004 \\
$y_{i t}^{2}$ & 0.1014 & 0.1983 & 0.1022 \\
$y_{i t}^{4}$ & 0.1024 & 0.2173 & 0.1050 \\
$x_{i t} y_{i t}$ & -0.0004 & -0.0055 & 0.0003 \\
$x_{i t}^{2} y_{i t}^{2}$ & 0.0461 & 0.0692 & 0.0411 \\
$x_{i t} y_{i t} x_{i t-5} y_{i t-5}$ & 0.0009 & 0.0017 & 0.0005 \\
$x_{i t}^{2} y_{i t-5}^{2}$ & 0.0322 & 0.0593 & 0.0279 \\
$y_{i t}^{2} x_{i t-5}$ & 0.0398 & 0.0765 & 0.0393 \\
$\mathrm{~N}$ & 20,762 & 15,478 & 19,430 \\
\hline
\end{tabular}

This table presents sample means over all $i$ and $t$ for which data on $x_{i t}$ and $y_{i t}$ are both available. $z_{x i t}$ is the excess $\log$ income of the wife from couple $i$ in year $t ; z_{y i t}$ is the excess log income of the husband from couple $i$ in year $t$. Sample sizes are smaller for the final three lead-lag moments. See text for details on variable construction

Table 4 Sources of bivariate excess kurtosis for couples' income changes: why do couples' large (absolute) income changes coincide?

\begin{tabular}{llll}
\hline & Raw & Permanent & Transitory \\
\hline Excess unconditional bivariate kurtosis, $\hat{\kappa}_{x y}$ & 1.53 & 0.52 & 0.98 \\
(z-stat) & $(7.58)$ & $(3.02)$ & $(4.71)$ \\
("wife-swap bootstrap" z-stat) & $(7.68)$ & $(3.28)$ & $(5.01)$ \\
\hline
\end{tabular}

Fraction explained by

\begin{tabular}{llll}
\hline Correlated variances, $\operatorname{cov}_{i}\left(\left(\sigma_{x}^{2} \mid i\right),\left(\sigma_{y}^{2} \mid i\right)\right)$ & $>38 \%$ & $>90 \%$ & $>28 \%$ \\
Covariance heterogeneity, $\operatorname{var}_{i}\left(\left(\sigma_{x y} \mid i\right)\right)$ & $>12 \%$ & $>33 \%$ & $>10 \%$ \\
Excess conditional bivariate kurtosis, $\kappa_{x y} \mid i$ & $<40 \%$ & $<-19 \%$ & $<55 \%$
\end{tabular}

$x_{i t} \equiv z_{x i t}-z_{x i t-1}$ and $y_{i t} \equiv z_{y i t}-z_{y i t-1}$ if raw estimate; $x_{i t} \equiv z_{x i t}-z_{x i t-1}$ and $y_{i t} \equiv z_{y i t+2}-z_{y i t-3}$ if permanent estimate; $x_{i t} \equiv z_{x i t+1}-z_{x i t}$ and $y_{i t} \equiv z_{y i t-1}-z_{y i t}$ if transitory estimate. z-statistics are against the null hypothesis is that $\kappa_{x y}=0$. The first $\mathrm{z}$-statistic assumes that observations are independent over time and across individuals. The second z-statistic uses the "wife-swap bootstrap" explained in the text. This implicitly assumes that $x_{i t}$ and $y_{i t}$ are unconditionally uncorrelated but allows $x_{i t}$ (and also $y_{i t}$ ) to be autocorrelated. The lower-bound on $\operatorname{cov}_{i}\left(\left(\sigma_{x}^{2} \mid i\right),\left(\sigma_{y}^{2} \mid i\right)\right)$ is calculated from the average of the sample covariance of $x_{i t}^{2}$ and $y_{i t-5}^{2}$ and the sample covariance of $y_{i t}^{2}$ and $x_{i t-5}^{2}$. The lower-bound on $\operatorname{var}_{i}\left(\left(\sigma_{x y} \mid i\right)\right)$ is calculated from the sample covariance of $x_{i t} y_{i t}$ and $x_{i t-5} y_{i t-5}$. The upper-bound on $\kappa_{x y} \mid i$ is calculated from these lower-bounds from Eq. (9). The percent of $\hat{\kappa}_{x y}$ explained by each of these components comes from Eq. (6) assuming that the other two components are zero 
assumption from the standard test that income changes are not autocorrelated; in the data, autocorrelations are negative for adjacent observations. The "wife-swap bootstrap" effectively provides a null hypothesis, showing how couples' incomes would jointly evolve if husbands and wives were paired at random (but each spouse's income was free to evolve individually as it did in the data). The rejection of this null suggests that couples' large income changes tend to coincide far more than would be expected from random pairing.

Two possible sources of this pattern of bivariate kurtosis reflect heterogeneity in couples' joint income dynamics: correlated variances of husbands' and their wives' income changes, and heterogeneity in the covariance of husbands' and their wives' incomes. Appendix shows how bivariate excess kurtosis can be decomposed into these components. Furthermore, that Appendix shows how panel data can be used to bound the relative size of these components. The lower panel of Table 4 presents results that bound these potential sources of bivariate kurtosis.

Correlated variances of couples' income changes, $\operatorname{cov}_{i}\left(\left(\sigma_{x}^{2} \mid i\right),\left(\sigma_{y}^{2} \mid i\right)\right)$ explain much of the tendency of couples' large (absolute) income changes to coincide. Husbands whose incomes are volatile have wives whose incomes are volatile. The measure of this based on 5-year leads and lags explains at least 38, 90, $28 \%$ of excess bivariate kurtosis for the raw, permanent and transitory measures of income changes, respectively. In the case of permanent variance, the large magnitude is particularly striking; husbands who receive large permanent shocks tend to have wives who receive large permanent shocks. This finding provides suggestive evidence of interest in models of assortative mating on risk (Chiappori and Reny 2006)

While there is evidence of persistent covariances (and therefore covariance heterogeneity, $\operatorname{var}_{i}\left(\left(\sigma_{x y} \mid i\right)\right)$, such heterogeneity is quantitatively smaller and accounts for far less of the observed excess bivariate kurtosis. If substantial heterogeneity in covariances exist in these data, they cannot be very persistent.

In the case of permanent income changes, observed excess bivariate kurtosis can be fully explained by correlated variances. In the case of transitory and raw income changes, substantial excess bivariate kurtosis remains unexplained. There is no way to know if this reflects parameter heterogeneity unexplained by the covariates used, reflects conditional excess bivariate kurtosis, or some combination.

It is worth noting that the relationship between husbands' (Winsorized, excess) $\log$ incomes and wives' (Winsorized, excess) log incomes is also present when looking at husbands' log incomes and a variety of work-related variables for wives. This is significant because couples' incomes may covary either because of variation in wages, in hours worked, or labor force participation. Adjustment in hours worked (and relatedly in home production in leisure) have been shown to be an important source of benefit in marriage (Vernon 2010).

Table 5 presents estimates of raw covariance and excess bivariate kurtosis (tendency of large absolute changes for the husband and wife to coincide) for several work-related variables for wives. ${ }^{5}$ The previous results examined the

\footnotetext{
5 Examining long-term changes in these work-related variables for husbands would be less fruitful, since there is less adjustment in hours and labor force participation for men than for women.
} 
Table 5 Raw covariance of husbands' excess log incomes with wives' excess hours, excess log incomes, and labor force participation

\begin{tabular}{lllll}
\hline Husband's variable: $y$ & \multicolumn{2}{l}{ Log income } & & \\
\cline { 2 - 5 } Wife's variable: $x$ & $\begin{array}{l}\text { Log } \\
\text { income }\end{array}$ & $\begin{array}{l}\text { Hours } \\
\text { worked }\end{array}$ & $\begin{array}{l}\text { Log income if } \\
\text { in labor force }\end{array}$ & In labor force \\
\hline Implied correlation & $-0.2 \%$ & $-3.3 \% *$ & $2.6 \% *$ & $-2.0 \% *$ \\
Excess kurtosis & $1.53^{*}$ & $0.91^{*}$ & 0.40 & $0.82^{*}$
\end{tabular}

Each column presents the estimates of the raw covariance, as discussed in the text. In each case, $y$ refers to the Winsorized excess log income of the husband The first row presents the implied sample correlation; the second row presents the implied excess kurtosis. "*” Indicates significance at the $5 \%$ level

relationship between changes in the excess log incomes of husbands and the excess $\log$ incomes of wives. Here, we look also at changes in excess hours (level of hours, not log hours, generated in the same way as excess log income) worked by wives, changes in excess log income for wives who remain working, and changes in labor force participation for wives. ${ }^{6}$ Note that all correlations are small and similar, between -4 and $3 \%$. Excess bivariate kurtosis is greater in the "hours worked" and "in labor force" measures than for the "income if in labor force measure"; the hypothesis that there is no tendency of couples' large income changes to coincide cannot be rejected conditioning on wives being in the labor force. This suggests that much of the variation of interest stems from changes in wives' hours; these hours changes tend to be large at the same time that husbands' incomes experience large changes.

\section{Conclusion}

This paper has decomposed observed bivariate kurtosis in couples' income changes; absolute income changes of husbands and wives tend to coincide. There is some evidence of heterogeneity across couples in the covariance parameter governing their of income changes; there is strong evidence that husbands' and wives' have correlated parameters governing the variances of their income changes. In the case of permanent income changes, these two forms of heterogeneity explain all observed bivariate kurtosis in couples' income changes.

The bounds on both forms of correlated heterogeneity identified here are useful for models of the household. The impact of intra-household risk-sharing (as proxied by the covariance parameter governing couples' income shocks) on savings, wealth or consumption will be attenuated-biased towards zero-in OLS regressions since couples' covariance parameters are measured with substantial error. For example,

\footnotetext{
${ }^{6}$ Excess hours are calculated just as excess log income but in levels and not logs, with Winsorizing at the 5th and 95th percent levels. Excess log income for wives who work are just as excess log income, but with any observations below the 5th percentile or above the 95th percentile dropped. Changes in labor force participation are -1 if wives leave the labor force, 0 if they remain in or out of the labor force during the period, and 1 if they enter the labor force. A wife is considered in the labor force if her income exceeds the 5th percentile level, so that it provides a complement to the previous variable. Unfortunately, hours data are too noisy to examine wives' wages, which are measured as the ratio of income to hours worked. This is problematic when hours worked are zero.
} 
Hess (2004) uses couples' covariances to predict divorce as a test of competing theories of marriage. Since instruments for couples' covariances are weak (and of dubious exogeneity), it is more fruitful to exploit the full range of variation in covariances in the data. To correct for the attenuation bias caused by including noisy measures of covariance as right-hand-side variables, we need the fraction of variation in parameter estimates that stems from variation in parameters (as opposed to estimation error). This paper provides an upper bound on the extent of attenuation bias in such regressions.

Furthermore, this paper documents a high correlation between husbands' and wives' income change variances. This positive assortative mating is what would be expected in a model of couple formation in which risk-aversion varies across individuals. To the degree that preferences are uniform but the technologies that produce volatile incomes vary across individuals, negative assortative mating would be predicted.

Open Access This article is distributed under the terms of the Creative Commons Attribution License which permits any use, distribution, and reproduction in any medium, provided the original author(s) and the source are credited.

\section{Appendix: Estimating sources of heterogeneity}

\section{Model}

Consider two variables, $x_{i}$ and $y_{i}$, that may not be independent of one another but are mutually independent across observations, $i$. In the case of couples' income changes studies in this paper, $x_{i}$ is the 1-year change in "excess" log income for a wife in couple $i$ and $y_{i}$ is the 1-year change in "excess" log income for her husband. ${ }^{7}$ The word "excess" (described in detail in Sect. 2) implies that any aggregate or predictable changes to income have been removed, so that $x_{i}$ and $y_{i}$ are residuals and therefore unconditionally mean zero by construction. ${ }^{8}$

Bivariate kurtosis has been used broadly to refer to the set of possible fourth moments coming from a pair of random variables: $E\left[x_{i}^{4}\right], E\left[x_{i}^{3} y_{i}\right], E\left[x_{i}^{2} y_{i}^{2}\right], E\left[x_{i} y_{i}^{3}\right]$ and $E\left[y_{i}^{4}\right]$. Mardia (1970) proposes a summary statistic that combines these. Here, I focus on the symmetric moment, $E\left[x_{i}^{2} y_{i}^{2}\right]$, because of the information that it encodes about correlated parameter heterogeneity, either the covariance between $\sigma_{x}^{2} \mid i$ and $\sigma_{y}^{2} \mid i$ across observations (denoted $\operatorname{cov}_{i}\left(\left(\sigma_{x}^{2} \mid i\right),\left(\sigma_{y}^{2} \mid i\right)\right)$ ) or heterogeneity across observations in $\sigma_{x y} \mid i$ (denoted $\operatorname{var}_{i}\left(\left(\sigma_{x y} \mid i\right)\right)$ ).

\footnotetext{
7 The choice of who is $x$ (wives) and who is $y$ (husbands) corresponds to the second sex chromosome (XX for women and XY for men).

${ }^{8}$ While the mean-zero assumption is not central here, it allows the unconditional expectations $E\left[x_{i}^{2}\right]$ and $E\left[y_{i}^{2}\right]$ to be relabeled $\sigma_{x}^{2}$ and $\sigma_{y}^{2}$ and called variances and allows the unconditional expectation $E\left[x_{i} y_{i}\right]$ to be relabeled $\sigma_{x y}$ and called a covariance. Since this paper considers latent heterogeneity, it admits the possibility that the variance-covariance matrix of couples' income changes may differ ex-ante (but unobservably) across observations, $i ; \sigma_{x}^{2}\left|i, \sigma_{y}^{2}\right| i$, and $\sigma_{x y} \mid i$ denote the elements of this matrix.
} 
If $x_{i}$ and $y_{i}$ have a conditionally bivariate normal distribution, then

$$
E\left[x_{i}^{2} y_{i}^{2} \mid i\right]=\left(\sigma_{x}^{2} \mid i\right)\left(\sigma_{y}^{2} \mid i\right)+2\left(\sigma_{x y} \mid i\right)^{2} .
$$

I follow Mardia's convention of using this jointly normal baseline. I refer to the symmetric bivariate analog to excess kurtosis as excess bivariate kurtosis:

$$
\begin{gathered}
\kappa_{x y} \mid i \equiv 3\left(\frac{E\left[x_{i}^{2} y_{i}^{2} \mid i\right]}{\left(\sigma_{x}^{2} \mid i\right)\left(\sigma_{y}^{2} \mid i\right)+2\left(\sigma_{x y} \mid i\right)^{2}}-1\right) \\
\kappa_{x y} \equiv 3\left(\frac{E\left[x_{i}^{2} y_{i}^{2}\right]}{\sigma_{x}^{2} \sigma_{y}^{2}+2 \sigma_{x y}^{2}}-1\right) .
\end{gathered}
$$

$\kappa_{x y} \mid i$ measures bivariate kurtosis conditioning on observation-specific parameters such as the variances of $x_{i}$ and $y_{i}$ for a given $i$; naturally, this is unobserved. $\kappa_{x y}$ measures unconditional bivariate kurtosis and is straightforward to estimate from its constituent parts. Under conditional bivariate normality, $\kappa_{x y} \mid i=0$. Note that if $x_{i}=y_{i}$, then measures of bivariate kurtosis collapse to the standard univariate definition of kurtosis.

To consider heterogeneity in lower (than fourth) order moments, I make the simplifying assumption that $\kappa_{x y} l i$ does not vary across observations. In this case, it is straightforward to rewrite Eq. (3) as:

$$
E\left[x_{i}^{2} y_{i}^{2} \mid i\right]=\left(\frac{\kappa_{x y} \mid i}{3}+1\right)\left(\left(\sigma_{x}^{2} \mid i\right)\left(\sigma_{y}^{2} \mid i\right)+2\left(\sigma_{x y} \mid i\right)^{2}\right)
$$

Subtracting $\left(\frac{\kappa \mid i}{3}+1\right)\left(\sigma_{x}^{2} \sigma_{y}^{2}+2 \sigma_{x y}^{2}\right)$ from both sides, taking expectations (where $E\left[E\left[x_{i}^{2} y_{i}^{2} \mid i\right]\right]=E\left[x_{i}^{2} y_{i}^{2}\right]$ by the law of iterated expectations), dividing by $\left(\sigma_{x}^{2} \sigma_{y}^{2}+2 \sigma_{x y}^{2}\right)$, and rearranging, Eq. (5) can be rewritten as:

$$
\kappa_{x y}=\kappa_{x y} \mid i+\left(\kappa_{x y} \mid i+3\right) \frac{\operatorname{cov}_{i}\left(\left(\sigma_{x}^{2} \mid i\right),\left(\sigma_{y}^{2} \mid i\right)\right)+2 \operatorname{var}_{i}\left(\left(\sigma_{x y} \mid i\right)\right)}{\sigma_{x}^{2} \sigma_{y}^{2}+2 \sigma_{x y}^{2}} .
$$

In other words, unconditional bivariate kurtosis $\left(\kappa_{x y}\right.$, which can be estimated from the data) reflects three (unobserved) factors:

1. conditional bivariate kurtosis, $\kappa_{x y} \mid i$;

2. covarying variances, $\operatorname{cov}_{i}\left(\left(\sigma_{x}^{2} \mid i\right),\left(\sigma_{y}^{2} \mid i\right)\right)$; and,

3. heterogeneous covariances, $\operatorname{var}_{i}\left(\left(\sigma_{x y} \mid i\right)\right)$.

In the first case, large income changes for husbands and wives tend to coincide (conditional on husbands' and wives' income variances and covariances); in the second case, husbands with high-variance income changes tend to have wives with the same; in the third case, some couples' incomes move together while others move in opposite directions. All three imply the tendency of large absolute income changes 
for husbands and wives to coincide. The $i$ subscript on the variance and covariance operators refer to the cross-section of conditional moments over observations $i$. For example, $\operatorname{var}_{i}\left(\left(\sigma_{x y} \mid i\right)\right)>0$ indicates that observations differ from one another in their ex-ante covariance, $\sigma_{x y} \mid i$. In the univariate case (setting $x_{i}=y_{i}$ so that $\kappa_{x} \mid i \equiv E\left[x_{i}^{4} \mid i\right] /\left(\sigma_{x}^{2} \mid i\right)^{2}-3$ and $\kappa_{x} \equiv E\left[x_{i}^{4}\right] /\left(\sigma_{x}^{2}\right)^{2}-3$, this reduces to:

$$
\kappa_{x}=\kappa_{x} \mid i+\left(\kappa_{x} \mid i+3\right) \frac{\operatorname{var}_{i}\left(\left(\sigma_{x}^{2} \mid i\right)\right)}{\left(\sigma_{x}^{2}\right)^{2}}
$$

Covariance heterogeneity and correlated variances appear identically in observed bivariate kurtosis. This is shown in the two panels of Fig. 2. The two panels present the same data, eight hypothetical observations (shown as circles, which are in the same locations in each panel) for $x_{i}$ and $y_{i}$. In particular, $x_{i}$ and $y_{i}$ both take on values of $-1,0$, and 1 with probabilities $(1 / 4,1 / 2,1 / 4)$ and therefore $E\left[x_{i}\right]=E\left[y_{i}\right]=0$ and $\sigma_{x}^{2}=\sigma_{y}^{2}=1 / 2$. Were $x_{i}$ and $y_{i}$ to be independent, $E\left[x_{i}^{2} y_{i}^{2}\right]=1 / 4$. $x_{i}$ and $y_{i}$ are not independent (though they are unconditionally uncorrelated, $\sigma_{x y}=0$ ) but the marginal distributions of $x_{i}$ and $y_{i}$ are unchanged. The key feature of this distribution is its excess bivariate kurtosis, the absence (compared with the distribution under independence) of mass where exactly one variable ( $x_{i}$ or $y_{i}$, but not both) is zero. Since non-zero values of $x_{i}$ and $y_{i}$ always coincide, the mean of $E\left[x_{i}^{2} y_{i}^{2}\right]=1 / 2$ compared to $1 / 4$ in the case of independence.

The two panels present different possible explanations for the bivariate kurtosis found in this hypothetical data: correlated variances $\left(\operatorname{cov}_{i}\left(\left(\sigma_{x}^{2} \mid i\right),\left(\sigma_{y}^{2} \mid i\right)\right)>0\right.$, right panel) or covariance heterogeneity $\left(\operatorname{var}_{i}\left(\left(\sigma_{x y} \mid i\right)\right)>0\right.$, left panel).

In the left panel, observations are either in a negative covariance state or a positive covariance state. Covariances, $\left(\sigma_{x y} \mid i\right)$, are either -1 (observations identified with a negative sign and running from top-left to bottom-right) or 1 (observations identified with a positive sign and running from bottom-left to topright) with equal probability. Conditional on the covariance, the distribution is trinomial (values of $-1,0$, and 1 are possible).
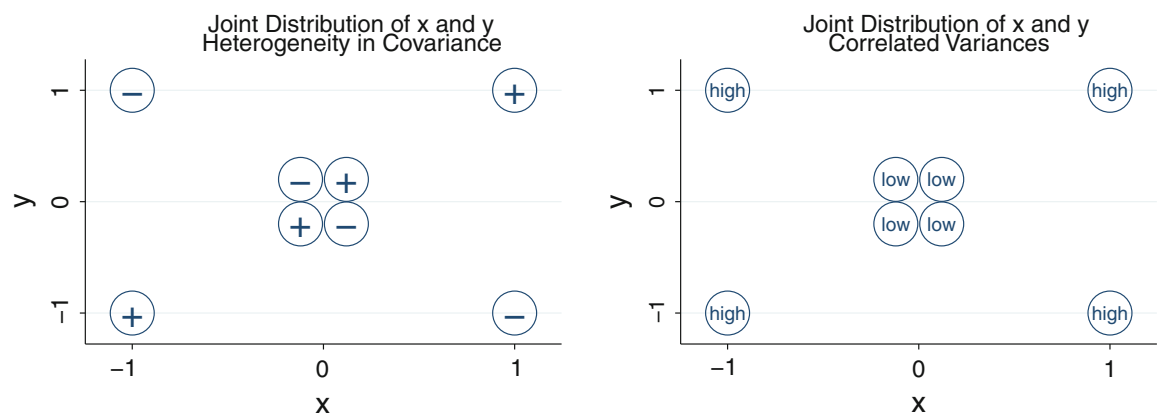

Fig. 2 Stylized joint distribution of couples' changes in income. Stylized depiction of the data. See text for details 
In the right panel, some observations are in a high variance state while others are in a low variance state. Variances, $\left(\sigma_{x}^{2} \mid i\right)$ and $\left(\sigma_{y}^{2} \mid i\right)$, are either both 0 (marked with a "low" and clustered at zero) or both 1 (marked with a "high" and found at the corners) for both $x_{i}$ and $y_{i}$ and the variances for $x_{i}$ and $y_{i}$ are perfectly correlated. Conditional on the variances, the distribution is binomial (values of -1 and 1 are possible in the high variance state while only values of 0 are possible in the low variance state).

If we observe the unconditional distribution depicted in these panels, where large absolute values of $x_{i}$ and $y_{i}$ tend to coincide, this could reflect either correlated variances or covariance heterogeneity. A third extreme possibility is that there is no ex-ante heterogeneity; unconditional bivariate kurtosis reflects conditional bivariate kurtosis and not correlated heterogeneity. In other words, all observations are drawn from the same distribution which has the feature that large absolute changes of $x_{i}$ and $y_{i}$ happen to coincide. Of course, any combination of conditional bivariate kurtosis, correlated variances, and covariance heterogeneity will be consistent with the unconditional joint distribution described here.

\section{Testing for correlated heterogeneity}

Here, I present distributions for a test statistic for unconditional bivariate kurtosis. The aim is to test the null that there is no excess unconditional bivariate kurtosis, the joint normal baseline.

Under the null hypothesis of no bivariate kurtosis when $\sigma_{x y}=0$ (a strong but testable assumption appropriate for the application to follow), for a randomly chosen $i$ from the population, $x_{i}^{2} y_{i}^{2}$ will have mean $\sigma_{x}^{2} \sigma_{y}^{2}$ and variance $\left(\operatorname{var}_{i}\left(\left(\sigma_{x}^{2} \mid i\right)\right)+\sigma_{x}^{4}\right) \kappa_{x}\left(\operatorname{var}_{i}\left(\left(\sigma_{y}^{2} \mid i\right)\right)+\sigma_{x}^{4} \sigma_{y}^{4}\right)$. This is merely the product of $E\left[x_{i}^{4}\right]$ and $E\left[y_{i}^{4}\right]$ less the square of the mean. Note that under the null hypothesis and assuming moments are finite, $\left(\operatorname{var}_{i}\left(\left(\sigma_{x}^{2} \mid i\right)\right)+\sigma_{x}^{4}\right) \kappa_{x}$ can be estimated with $\frac{1}{N} \Sigma_{i} x_{i}^{4}$ and $\left(\operatorname{var}_{i}\left(\left(\sigma_{y}^{2} \mid i\right)\right)+\sigma_{y}^{4}\right) \kappa_{y}$ can be estimated with $\frac{1}{N} \Sigma y_{i}^{4}$. Since observations are assumed to be iid, under the null hypothesis with $\sigma_{x y}=0$ the sample variance of $x_{i} y_{i}, \frac{1}{N} \Sigma_{i} x_{i}^{2} y_{i}^{2}-\left(\frac{1}{N} \Sigma_{i} x_{i} y_{i}\right)^{2}$ will have mean $\bar{\sigma}_{x}^{2} \bar{\sigma}_{y}^{2}$ and variance $\frac{1}{N}\left(\left(\operatorname{var}_{i}\left(\sigma_{x}^{2} \mid i\right)+\sigma_{x}^{4}\right)\right.$ $\left.\kappa_{x}\left(\operatorname{var}_{i}\left(\sigma_{y}^{2} \mid i\right)+\sigma_{y}^{4}\right) \kappa_{y}-\sigma_{x}^{4} \sigma_{y}^{4}\right)$ Since we have the distribution of the sample variance it is straightforward to test that null.

Formally, the sample moment $\frac{1}{N} \sum_{i} x_{i}^{2} y_{i}^{2}$ just allows for a test of the independence of shocks, $E\left[f\left(x_{i}\right) f\left(y_{i}\right)\right]=E\left[f\left(x_{i}\right)\right] E\left[f\left(y_{i}\right)\right]$. Independence requires that this be true for all $f()$ and $g()$ and here we look only at second moments, $f\left(x_{i}\right)=x_{i}^{2}$ and $g\left(y_{i}\right)=y_{i}^{2}$. The novelty here is that Eq. (6) decomposes this particular rejection of independence into conditional bivariate kurtosis and two types of latent correlated heterogeneity. In the example that follows, such correlated heterogeneity is of economic interest. Do all couples' incomes jointly evolve in the same way? 
"Wife-swap bootstrap"

So far, $\left\{x_{i}, y_{i}\right\}$ pairs have been assumed to be independent of other pairs. For a cross-section of randomly chosen individuals who face idiosyncratic shocks, this assumption may be relatively innocuous. When data comes from a panel, this is seldom true. I add time subscripts (e.g., $x_{i t},\left(\sigma_{y}^{2} \mid i, t\right)$ ) to accommodate autocorrelation. In this case, the sample variance, $\frac{1}{N} \frac{1}{T} \Sigma_{i} \Sigma_{t} x_{i t}^{2} y_{i t}^{2}-\left(\frac{1}{N} \frac{1}{T} \Sigma_{i} \Sigma_{t} x_{i t} y_{i t}\right)^{2}$ will be drawn from a distribution with same mean as in the i.i.d. case, $\sigma_{x}^{2} \sigma_{y}^{2}$, but not the same variance:

$$
\begin{aligned}
\frac{1}{N} & \frac{1}{T} \Sigma_{i} \Sigma_{t} x_{i t}^{2} y_{i t}^{2}-\left(\frac{1}{N} \frac{1}{T} \Sigma_{i} \Sigma_{t} x_{i t} y_{i t}\right)^{2} \\
& \sim\left(\sigma_{x}^{2} \sigma_{y}^{2}, \frac{1}{N T}\left(\begin{array}{c}
\left(\operatorname{var}_{i}\left(\left(\sigma_{x}^{2} \mid i, t\right)\right)+\sigma_{x}^{4}\right) \kappa_{x}\left(\operatorname{var}_{i}\left(\left(\sigma_{y}^{2} \mid i, t\right)\right)+\sigma_{y}^{4}\right) \kappa_{y}-\sigma_{x}^{4} \sigma_{y}^{4} \\
+\frac{1}{T} \Sigma_{i} \Sigma_{t} \Sigma_{s \neq t} \operatorname{cov}\left(x_{i s}^{2} y_{i s}^{2}, x_{i t}^{2} y_{i t}^{2}\right)
\end{array}\right)\right)
\end{aligned}
$$

The first part of the variance (same as in the i.i.d. case) is trivial to estimate from sample data as

$$
\frac{1}{N T}\left(\frac{1}{N^{2} T^{2}} \Sigma_{i} \Sigma_{t} x_{i t}^{4} \Sigma_{i} \Sigma_{t} y_{i t}^{4}-\frac{1}{N^{4} T^{4}}\left(\Sigma_{i} \Sigma_{t} x_{i t}^{2}\right)^{2}\left(\Sigma_{i} \Sigma_{t} y_{i t}^{2}\right)^{2}\right)
$$

covariance terms (stemming from autocorrelation) are more difficult to estimate. The main challenge in a non-rectangular panel is that attrition may be related to the autocorrelation. Without attrition, $\operatorname{cov}\left(x_{i s}^{2} y_{i s}^{2}, x_{i t}^{2} y_{i t}^{2}\right)$ can be estimated from data under the null as $\frac{1}{N} \Sigma_{i} x_{i s}^{2} x_{i t}^{2} \frac{1}{N} \Sigma_{i} y_{i s}^{2} y_{i t}^{2}$. An alternative way to obtain the same variance can be obtained by noting that under the null, $\operatorname{var}\left(\frac{1}{N} \frac{1}{T} \Sigma_{i} \Sigma_{t} x_{i t}^{2} y_{i t}^{2}\right)=\operatorname{var}\left(\frac{1}{N} \frac{1}{T} \Sigma_{i} \Sigma_{t} x_{i t}^{2} y_{j t}^{2}\right)$ for a randomly chosen $j \neq i$. (The non-rectangularity problem can be overcome if $j$ is chosen so that $i$ and $j$ have the same number of observations.) As a result, it is straightforward obtain the variance of the estimator by repeatedly sampling $\frac{1}{N} \frac{1}{T} \Sigma_{i} \Sigma_{t} x_{i t}^{2} y_{j t}^{2}$ for different choices of $j$ and taking the variance of these. When $x$ and $y$ refer to the incomes of husbands and wives, this involves randomly pairing all husbands and wives from the data, and calculating the estimator for this synthetic pair. Doing this repeatedly builds up a reference distribution under the null. I use the tongue-in-cheek name wife-swap bootstrap to refer to this procedure.

\section{Bounding correlated heterogeneity}

After rejecting the null of no excess bivariate kurtosis (because $\kappa_{x y}>0$ ), we know that $\operatorname{cov}_{i}\left(\left(\sigma_{x}^{2} \mid i\right),\left(\sigma_{y}^{2} \mid i\right)\right)>0, \operatorname{var}_{i}\left(\sigma_{x y} \mid i\right)>0, \kappa_{x y} \mid i>0$, or some combination of these. $\operatorname{var}_{i}\left(\left(\sigma_{x y} \mid i\right)\right)>0$ indicates that the covariance differs across observations. $\operatorname{cov}_{i}\left(\left(\sigma_{x}^{2} \mid i\right),\left(\sigma_{y}^{2} \mid i\right)\right)>0$ indicates that observations with high-variance $x$ also tend 
to have high-variance $y$. While identified from the same moment in the data $\frac{1}{N} \sum_{i} x_{i}^{2} y_{i}^{2}$, they reflect completely different phenomenon Consider the application to couples, and $x$ refers to the change in husbands' incomes and $y$ refers to the change in wives' incomes. $\operatorname{var}_{i}\left(\left(\sigma_{x y} \mid i\right)\right)>0$ could be interpreted as saying that the diversification benefits of marriage (proxied by $\left(\sigma_{x y} \mid i\right)$ vary across couples. By contrast, $\operatorname{cov}_{i}\left(\left(\sigma_{x}^{2} \mid i\right),\left(\sigma_{y}^{2} \mid i\right)\right)$ identifies assortative mating in risk, which could be a test of models of optimal partner selection.

Without additional information from covariates, conditional kurtosis, correlated variances and covariance heterogeneity are observationally equivalent. To separate them, we must use covariates $Z_{i}$ to obtain observation-specific estimates of $\left(\sigma_{x}^{2} \mid i\right)$, $\left(\sigma_{y}^{2} \mid i\right)$, and $\left(\sigma_{x y} \mid i\right)$, and then identify the heterogeneity in $\left(\sigma_{x y} \mid i\right)$ or correlated heterogeneity in $\left(\sigma_{x}^{2} \mid i\right)$ and $\left(\sigma_{y}^{2} \mid i\right)$ that can be traced out by variation in $Z_{i}$. Consider the following set of regressions (where each element of $x_{i}, \mu_{x i}$, etc, refers to a vector):

$$
\left(\begin{array}{c}
x_{i}^{2} \\
y_{i}^{2} \\
x_{i} y_{i}
\end{array}\right)=Z_{i} \times\left(\begin{array}{c}
\beta_{x} \\
\beta_{y} \\
\beta_{x y}
\end{array}\right)+\left(\begin{array}{c}
\mu_{x i} \\
\mu_{y i} \\
\mu_{x y i}
\end{array}\right) .
$$

Variation in $\left(\sigma_{x y} \mid i\right)$ traced out by $Z_{i}$ places a lower bound on $\operatorname{var}_{i}\left(\left(\sigma_{x y} \mid i\right)\right) \geq \beta_{x y} Z^{\prime} Z \beta_{x y}$; correlated variation in $\left(\sigma_{x}^{2} \mid i\right)$ and $\left(\sigma_{y}^{2} \mid i\right)$ traced out by $Z_{i}\left(\beta_{x} Z^{\prime} Z \beta_{y}\right)$ provides one source of $\operatorname{cov}_{i}\left(\left(\sigma_{x}^{2} \mid i\right),\left(\sigma_{y}^{2} \mid i\right)\right) \cdot{ }^{9}$. Since additional correlated variation in variances could be of either sign, the total magnitude of correlated variation in variances is not bounded by $\beta_{x} Z^{\prime} Z \beta_{y}$. Having said that, the panel data approach outlined in section "Panel data" provides a setting where this is likely to be a lower bound.

From Eq. (6), lower bounds on $\operatorname{var}_{i}\left(\left(\sigma_{x y} \mid i\right)\right)$ and $\operatorname{cov}_{i}\left(\left(\sigma_{x}^{2} \mid i\right),\left(\sigma_{y}^{2} \mid i\right)\right)$ imply an upper bound on the importance of conditional bivariate kurtosis in explaining unconditional bivariate kurtosis. These are the upper-bounds for the importance of conditional bivariate kurtosis under the assumption that $\kappa_{x y} l i$ (defined in Eq. 3) are the same across individuals:

$$
\kappa_{x y} \mid i \leq \frac{\kappa_{x y}\left(\sigma_{x}^{2} \sigma_{y}^{2}+2 \sigma_{x y}^{2}\right)-3\left(\beta_{x} Z^{\prime} Z \beta_{y}+2 \beta_{x y} Z^{\prime} Z \beta_{x y}\right)}{\sigma_{x}^{2} \sigma_{y}^{2}+2 \sigma_{x y}^{2}+\beta_{x} Z^{\prime} Z \beta_{y}+2 \beta_{x y} Z^{\prime} Z \beta_{x y}}
$$

Note that all of the objects on the right-hand side of these inequalities can be estimated.

\footnotetext{
9 This bears some similarity to Mardia and Marshall (1984) who provide maximum likelihood estimates of covariance heterogeneity (traced out by parametric variation) in a conditionally normal setting.
} 
Panel data

While panel data complicates estimation of unconditional bivariate kurtosis (see section "Wife-swap bootstrap"), it also provides additional information useful in decomposing it. Couples $i$ may differ from one another in their covariance parameter, $\left(\sigma_{x y} \mid i\right)$; and husbands with high variance parameters $\left(\sigma_{y}^{2} \mid i\right)$ may have wives with high variance parameters $\left(\sigma_{x}^{2} \mid i\right)$. With multiple observations from each couple, couple-specific estimates become possible. I assume that there exist $s$ and $t$ sufficiently far apart (for example, a fixed distance $k$ ) that common shocks from the two periods are uncorrelated. In the example that follows, I use $s=t-5$. These assumptions are strong, but are readily testable in the case of couples, whose nonoverlapping income changes are nearly uncorrelated and where any changes in the distribution of parameters is slow. For example, Abowd and Card (1989) show that innovations to income are not autocorrelated at lags greater than two years. Most obviously, note that $\left|\operatorname{cov}_{i}\left(\left(\sigma_{x y} \mid i s\right),\left(\sigma_{x y} \mid i t\right)\right)\right| \leq \sqrt{\operatorname{var}_{i}\left(\sigma_{x y} \mid i s\right) \operatorname{var}_{i}\left(\sigma_{x y} \mid i t\right)}$. If the distribution of $\sigma_{x y} \mid i$ is stable, then this implies $\left|\operatorname{cov}_{i}\left(\left(\sigma_{x y} \mid i s\right),\left(\sigma_{x y} \mid i t\right)\right)\right|$ $\leq \operatorname{var}_{i}\left(\sigma_{x y} \mid i t\right)$ (the last equality by the stability assumption). $\operatorname{cov}_{i}\left(\left(\sigma_{x y} \mid i s\right)\right.$, $\left.\left(\sigma_{x y} \mid i t\right)\right)$ can be readily estimated from the data as $\frac{1}{N T} \Sigma_{t} \Sigma_{i}\left(x_{i s} y_{i s} x_{i t} y_{i t}-\hat{\sigma}_{x y}^{2}\right)$, and this provides a lower bound for $\operatorname{var}_{i}\left(\sigma_{x y} \mid i t\right)$.

While it is not strictly required by the assumptions above, all but the most pathological distributions will exhibit

$$
\begin{aligned}
& \frac{1}{2}\left|\operatorname{cov}_{i}\left(\left(\sigma_{x}^{2} \mid i s\right),\left(\sigma_{y}^{2} \mid i t\right)\right)+\operatorname{cov}_{i}\left(\left(\sigma_{x}^{2} \mid i t\right),\left(\sigma_{y}^{2} \mid i s\right)\right)\right| \\
& \quad<\frac{1}{2}\left(\operatorname{cov}_{i}\left(\left(\sigma_{x}^{2} \mid i s\right),\left(\sigma_{y}^{2} \mid i s\right)\right)+\operatorname{cov}_{i}\left(\left(\sigma_{x}^{2} \mid i t\right),\left(\sigma_{y}^{2} \mid i t\right)\right)\right) \\
& \quad=\operatorname{cov}_{i}\left(\left(\sigma_{x}^{2} \mid i t\right),\left(\sigma_{y}^{2} \mid i t\right)\right)
\end{aligned}
$$

where the last equality follows from stability. Contemporaneous shocks should be more highly correlated than lead or lagged shocks with a large enough time-gap. This need not be true when one variable predicts subsequent values for other, but when $\left(\left(\sigma_{x}^{2} \mid i s\right),\left(\sigma_{y}^{2} \mid i t\right)\right)$ and $\operatorname{cov}_{i}\left(\left(\sigma_{x}^{2} \mid i t\right),\left(\sigma_{y}^{2} \mid i s\right)\right)$ are positive and similar in value, contemporaneous shocks are more likely to have similar magnitudes. $\left(\left(\sigma_{x}^{2} \mid i s\right),\left(\sigma_{y}^{2} \mid i t\right)\right)$ and $\operatorname{cov}_{i}\left(\left(\sigma_{x}^{2} \mid i t\right),\left(\sigma_{y}^{2} \mid i s\right)\right)$ can be readily estimated from the data with $\frac{1}{N T} \Sigma_{t} \Sigma_{i}\left(x_{i s}^{2} y_{i t}^{2}-\hat{\sigma}_{x}^{2} \hat{\sigma}_{y}^{2}-2 \hat{\sigma}_{x y}^{2}\right)$ and $\frac{1}{N T} \Sigma_{t} \Sigma_{i}\left(x_{i t}^{2} y_{i s}^{2}-\hat{\sigma}_{x}^{2} \hat{\sigma}_{y}^{2}-2 \hat{\sigma}_{x y}^{2}\right)$, respectively. This estimates a lower bound on $\operatorname{cov}_{i}\left(\left(\sigma_{x}^{2} \mid i t\right),\left(\sigma_{y}^{2} \mid i y\right)\right)$ as

$$
\frac{1}{N T} \Sigma_{t} \Sigma_{i}\left(\frac{1}{2} x_{i s}^{2} y_{i t}^{2}+\frac{1}{2} x_{i t}^{2} y_{i s}^{2}-\hat{\sigma}_{x}^{2} \hat{\sigma}_{y}^{2}-2 \hat{\sigma}_{x y}^{2}\right) \text {. }
$$




\section{References}

Abowd, J., \& Card, D. (1989). On the covariance structure of earnings and hours changes. Econometrica, 57(2), 411-445.

Batchelder, L. L. (2003). Can families smooth variable earnings? Harvard Journal on Legislation, 40(2), 395-452.

Becker, G. S. (1973). A theory of marriage: Part I. Journal of Political Economy, 81(4), 813-846.

Bollinger, C., Luis, G., \& Ziliak, J. P. (2009). Welfare reform and the level and composition of income. In J. P. Ziliak (Ed.), Welfare reform and its long-term consequences for America's poor (pp. 59-103). Cambridge, UK: Cambridge University Press.

Browning, M., Ejrnæs, M., \& Alvarez, J. (2010). Modelling income processes with lots of heterogeneity. Review of Economic Studies, 77, 1353-1381.

Burtless, G. (1990). Comment on M. Hurd's 'The Joint Retirement Decisions of Husbands and Wives'. In D. A. Wise (Ed.), Issues in the economics of aging. Chicago: University of Chicago Press.

Cameron, S., \& Tracy, J. (1998). Earnings variability in the United States: An examination using Matched-CPS data. Working Paper.

Carroll, C. D., \& Samwick A. A. (1997). The nature of precautionary wealth. Journal of Monetary Economics, 40(1), 41-71.

Casanova, M. (2010). Happy together: A structural model of couples' joint retirement choices. Working Paper.

Chami, R., \& Hess, G. D. (2005). For better or for worse? State-level marital formation and risk sharing. Review of Economics of the Household, 3(4), 1569-5239.

Chiappori, P.-A., \& Reny, P. J. (2006). Matching to share risk. Working Paper.

Comin, D., Groshen, E. L., \& Rabin, B. (2009). Turbulent firms, turbulent wages? Journal of Monetary Economics, 56(1), 109-133.

Cullen, J. B., \& Gruber, J. (2000). Does unemployment insurance crowd out spousal labor supply? Journal of Labor Economics, 18(3), 546-72.

Dahl, M., DeLeire, T., \& Schwabish, J. (2007). Trends in earnings variability over the past 20 years. Washington, DC: Congressional Budget Office.

Daly, M. C., \& Duncan, G. J. (1997). Earnings mobility and instability, 1969-1995. Working Paper.

Dynan, K. E., Elmendorf, D. W., \& Sichel, D. E. (2007). The evolution of earnings and income volatility. Working Paper, Federal Reserve Board.

Dynarski, S., \& Gruber, J. (1997). Can families smooth variable earnings? Brookings Papers on Economic Activity, 1997(1), 229-303.

Geweke, J. F., \& Keane, M. (2000). An empirical analysis of income dynamics among men in the PSID: 1968-1989. Journal of Econometrics, 96, 293-356.

Gottschalk, P., \& Moffitt, R. A. (1994). The growth of earnings instability in the U.S. labor market. Brookings Papers on Economic Activity, 1994(2), 217-272.

Gottschalk, P., \& Moffitt, R. (2002). Trends in the transitory variance of earnings in the United States. Economic Journal, 112, C68-C73.

Gottschalk, P., \& Moffitt, R. (2006). Trends in earnings volatility in the U.S.: 1970-2002. Working Paper.

Gustman, A., \& Steinmeier, T. (2000). Retirement in dual-career families: A structural model. Journal of Labor Economics, 18(3), 503-545.

Hacker, J. (2006). The great risk shift: The assault on American jobs, families, health care, and retirement; and how you can fight back. Oxford: Oxford University Press.

Haider, S. J. (2001). Earnings instability and earnings inequality in the United States, 1967-1991. Journal of Labor Economics, 19(4), 799-836.

Hall, R. E., \& Mishkin, F. S. (1982). The sensitivity of consumption to transitory income: Estimates from panel data on households. Econometrica, 50, 461-481.

Hertz, T. (2006). Understanding mobility in America. Center for American Progress Discussion Paper.

Hess, G. D. (2004). Marriage and consumption insurance: What's love got to do with it? Journal of Political Economy, 112(2), 290-318.

Hurd, M. (1990). The joint retirement decisions of husbands and wives. In D. A. Wise (Ed.), Issues in the economics of aging. Chicago: University of Chicago Press.

Hyslop, D. R. (2001). Rising U.S. earnings inequality and family labor supply: The covariance structure of intrafamily earnings. American Economic Review, 91(4), 755-777. 
Jensen, S. T., \& Shore, S. H. (2011). Semi-parametric bayesian modelling of income volatility heterogeneity. Journal of the American Statistical Association, 106(496), 1280-1290.

Jensen, S. T., \& Shore, S. H. (2012). Changes in the distribution of income volitility. Working Paper, Johns Hopkins University.

Leete, L., \& Bania, N. (2010). The effect of income shocks on food insufficiency. Review of Economics of the Household, 8(4), 505-526.

Lundberg, S. (1985). The added worker effect. Journal of Labor Economics, 3(1), 11-37.

Maestas, N. (2001). Labor, love, and leisure: complementarity and the timing of retirement by working couples. Berkeley, CA: Mimeo, University of California at Berkeley.

Mardia, K. (1970). Measures of multivariate skewness and kurtosis with applications. Biometrika, 36, 519-530.

Mardia, K. (1974). Applications of some measures of multivariate skewness and kurtosis in testing normality and robustness studies. Sankhya: The Indian Journal of Statistics, Series B, 36(2), $115-128$.

Mardia, K. (1980). Tests of univariate and multivariate normality. In E. Kotz (Ed.), Handbook of statistics (Vol. 1, pp. 279-320). New York: Wiley.

Mardia, K., \& Marshall, R. (1984). Maximum likelihood estimation of models for residual covariance in spatial regression. Biometrika, 71(1), 135-146.

Meghir, C., \& Pistaferri, L. (2004). Income variance dynamics and heterogeneity. Econometrica, 72(1), $1-32$.

Michaud, P. (2003). Joint labur supply dynamics of older couples. IZA Discussion Paper 832.

Moffitt, R. A., \& Gottschalk, P. (2011). Trends in the covariance structure of earnings in the U.S., 1969-1987. Journal of Economic Inequality, 9(3), 439-459.

Nordblom, K. (2004). Cohabitation and marriage in a risky world. Review of Economics of the Household, 2(3), 325-340.

Shin, D., \& Solon G. (2011). Trends in men's earnings volatility: What does the panel study of income dynamics show? Journal of Public Economics, 95(7-8), 973-982.

Shore, S. H. (2010). For better, for worse: Intrahousehold risk-sharing over the business cycle. Review of Economics and Statistics, 92(3), 536-548.

Vernon, V. (2010). Marriage for love, for money... and for time? Review of the Economics of the Household, 8(4), 433-457.

Winship, S. (2007). Income volatility, the great risk shift, and the democratic agenda. Working Paper. 